\title{
O PESQUISADOR DE PALAVRAS E O PESQUISADOR DE IMAGENS: REFLEXÕES SOBRE A ORGANIZAÇÃO DE BANCOS DE DADOS DE IMAGENS EM ARTES
}

\author{
Vanda de Fátima Fulgêncio de Oliveira
}

Resumo: Neste artigo, salienta-se a importância da garantia literária e do endosso dos usuários nos Sistemas de Recuperação de Informações em Artes a partir de uma análise da literatura sobre as especificidades de pesquisa de imagens em Artes e das metodologias utilizadas na indexação para Banco de Imagens. Considera-se nesta análise os aspectos ideológicos e conotativos da leitura do indexador e destaca-se os debates na área de terminologia.

Palavras-chave: Banco de Imagens, Indexação, Sistemas de Recuperação de Informações, Artes

\begin{abstract}
This article points out the importance of literary warranty and users' support in Arts Information Retrieval Systems, starting from a literature analysis about the searching specificity of images in Arts Sciences and the methodology used to index in Image Databases. The analysis takes into account the connotative and ideological aspects of the indexer technical reading and emphasizes the discussions on terminology.
\end{abstract}

Keywords: Image Databases; Indexing; Information Retrieval Systems, Art 


\section{A PESQUISA DE IMAGENS}

Os recentes desenvolvimentos das tecnologias de informação: novos processadores, discos rígidos com maior capacidade de armazenamento e melhora nos sistemas de compressão ${ }^{1}$ parecem indicar o fim dos problemas na área de Banco de Dados de Imagens. No entanto, em pesquisa realizada sobre formas de buscas de imagens na Internet percebemos que a simples digitalização das imagens e a sua disponibilização na Internet não oferece para o pesquisador muitas facilidades.

Entre as várias tentativas, nas diversas ferramentas de buscas, encontramos alguns parâmetros que podem “filtrar' o resultado da pesquisa. Podemos indicar por exemplo uma opção entre fotografias ou ilustrações, branco e preto ou colorida e também o formato da imagem. Essas opções irão alterar o meu resultado. Os diversos índices e catálogos não utilizam os mesmos critérios para a recuperação das informações.

O índice altavista ${ }^{2}$, por exemplo, oferece campos e atributos específicos para pesquisas de imagens como: tipos de imagens (fotos, elementos gráficos, botões/faixais, cor, P \& B) e Fontes: tipos de sites a serem pesquisados, incluindo aqui os sites comerciais que vendem imagens. O resultado da pesquisa oferece a imagem, o nome do arquivo, as dimensões da imagem em pixel, o tamanho do arquivo e a Fonte da Imagem se a mesma for conhecida.

É interessante observar que o link "semelhante" quando ativado gera uma página com conteúdo que coincide com sua pesquisa. A semelhança baseia-se em características visuais, dominantes, formatos e texturas. $\mathrm{O}$ que significa que uma imagem pode ser igual ou totalmente diferente.

Esses parâmetros podem "cercear" a pesquisa, no entanto não garantem que todas as vezes que eu digitar "crianças" vou encontrar imagens de crianças. Ou seja, a imagem pode não ser de uma criança, mas o nome da imagem ou o texto associado à imagem recuperada poder estar ligado a expressão “crianças”. 
Quando, por exemplo, a minha busca é por imagens de Sebastião Salgado rapidamente tenho um bom resultado. O nome do fotógrafo já está associado às suas fotografias. Quando eu quero uma imagem, e não tenho as "palavras certas" para a busca eu recupero uma diversidade de informações que muitas vezes nem mesmo se referem a alguma imagem.

Em um trabalho sobre sistema de informação em artes e atividades culturais, Pinheiro (1994) afirma que "não se pode mais considerar como informação em arte e cultura a simples representação do documento ou objeto, ou seja, o dado, mais o próprio documento ou objeto, ou seja, ao vivo, em cores e em movimento e texto integral".

Segundo a autora, a biblioteca, o centro de documentação/informação, o museu e o arquivo podem ser virtuais devido aos baixos custos de gravação, armazenagem e manipulação de enorme quantidades de imagens e registros sonoros. "A recuperação de informação pode ser, portanto, mais ágil, até mesmo permitindo a indexação automática e pesquisa no próprio documento" (PINHEIRO, 1994, p.332).

Essa temática é colocada no sentido de questionar o uso da tecnologia de digitalização de imagens e a titulação dada a estas imagens, fotografias ou figuras pelo autor da imagem, técnico "indexador" ou "internauta" e também como os mecanismos buscam essas imagens na rede, para esta finalidade vamos analisar uma suposta Iconoteca $^{3}$ baseada unicamente na conotação dada pelos usuários às imagens armazenadas.

\section{A ICONOTECA INTELIGENTE DE RODRIGUEZ}

Vícen Rodriguez (1995, p.356) retoma a discussão sobre a iconoteca O autor declara que os critérios de arquivamento, classificação e consulta válidos para documentos escritos parecem inadequados quando se ensaia seu uso nos bancos de imagens e propõe uma iconoteca inteligente que poderia se aproximar da iconoteca dos nossos sonhos. Dessa forma ele pede que imaginemos uma iconoteca. A iconoteca conta com um certo número de imagens em memória. Cada dia, o encarregado da manutenção da iconoteca introduz no sistema um par de novas imagens. A cada imagem é atribuída uma ficha virtual, um registro

${ }^{3}$ Serviço de arquivamento e consulta no qual o material é constituído por imagens.

(c) ETD - Educação Temática Digital, Campinas, SP, v.6, n.1, p.10-22 , dez. 2004 - ISSN: 1676-2592. 
no qual se fixam entradas, termos que se associam à imagem. No dia da inauguração da iconoteca, as fichas de todas as imagens estão vazias, não levam nenhum termo. O primeiro usuário se situa diante do sistema e tecla "chuva". O sistema mostra uma série de imagens. O sistema, depois de buscar o termo "chuva" nas fichas das imagens e de não o encontrar, seleciona uma série de imagens ao acaso.

Suponhamos que as imagens mostradas sejam vinte. Destas vinte imagens, o usuário descarta dez e fica com as outras dez. Nas fichas das dez imagens que considera válidas escreve-se o termo "chuva".

Uma vez que o usuário se tenha dado por satisfeito, pode-se pedir a ele que introduza novos termos para as imagens que considerou válidas. Introduz novos termos para cinco das dez imagens. Os novos termos são: “água”, "barro", "natureza”, “criança” e "povo". Cada um dos novos termos se acrescenta à ficha da imagem correspondente.

Segundo o autor "um sistema assim operaria com conotações e 'aprenderia' cada vez que alguém fizesse uso dele". Sugere ainda que para o correto funcionamento do sistema, seria recomendável que, ainda que o pesquisador encontrasse em várias fichas o termo introduzido para a seleção, o sistema também mostrasse algumas imagens eleitas ao acaso. “Às fichas poderia ser associado um contador que registrasse as vezes em que se ligou um termo a uma imagem".

De acordo com Rodriguez essa iconoteca seria "um sistema que continuamente, mediante seu uso, estaria tentando adaptar-se ao seu entorno".

A Iconoteca aparentemente operaria com conotações, o que se opõe aos sistemas baseados na definição de campos onde fizessem constar traços pertinentes.

A preocupação do autor se refere ao fato de que os traços pertinentes quando se está pensando em uma imagem pode ser infinito, dependendo apenas do olhar do pesquisador. Dessa forma, ao se optar por alguns traços pertinentes outros passos estarão sendo desprezados. Portanto, os traços pertinentes serão escolhidos de acordo com a previsão da demanda do usuário. 
Os traços considerados pertinentes o serão em função de como se esteja prevendo que a informação venha a ser solicitada, do modo de consulta da base de dados, que pode obedecer a um hábito ou a uma maneira de ver aquilo sobre o qual se pergunta (RODRIGUEZ, 1995, p. 352).

Qual a especificidade da imagem, o que significa uma imagem? O que representa uma imagem? A questão da representação e da significação é um tanto complexa.

As imagens significam coisas, não unicamente representam alguma coisa, para Rodriguez (1995, p.355) as imagens significam coisas muito diferentes do que poderíamos dizer que mostram "Em outras palavras: as imagens dissolvem as distinções entre denotação e conotação". Não apenas indicam, representam, como também conotam, ou seja, se submetem à compreensão e à subjetividade ${ }^{4}$. "A partir do momento em que a cultura se apodera do texto icônico - e a cultura já está presente no espírito do criador de imagens -, ele, como todos os outros textos, é oferecido à impressão da figura e do discurso" (MERTZ, 1974, p.10).

De acordo com Metz (1974) não podemos opor o "verbal" e o "visual" como dois grandes blocos homogêneos, um desprovido de contato com o outro, ou seja, o todo das mensagens materialmente visuais desempenha um papel considerável em mensagens não visuais, "o mundo visível e a língua não são estranhos um ao outro...” (MERTZ, 1974, p.12). Para o autor não podemos encerrar a imagem em um universo autônomo e separado da linguagem, dessa forma propõe o cruzamento da imagem e da linguagem.

A "imagem" não se constitui em um império autônomo e cerrado, um mundo fechado sem comunicação com o que o rodeia. As imagens- como as palavras, como todo o resto - não poderiam deixar de ser "consideradas" nos jogos do sentido, nos mil movimentos que vem regular a significação no seio das sociedades (MERTZ, 1974, p. 10).

\section{O PESQUISADOR DE PALAVRAS}

Mas afinal do que se trata a indexação? Para quê? E para quem? É interessante observar que antigos "segredos" utilizados somente pelos profissionais da informação (bibliotecários, documentalistas, terminólogos) ao organizarem informações, em acervos ou

\footnotetext{
${ }^{4}$ Um termo é chamado denotativo quando cobre uma definição que visa a esgotar um conceito do ponto de vista de sua extensão. Um termo será chamado conotativo se, ao ser denominado um dos atributos do conceito considerado do ponto de vista de sua compreensão, ele remete ao conceito tomado na sua totalidade. Cf.: GREIMAS, A. J.; COURTÉS, J. Dicionário de Semiótica. São Paulo: Cultrix, 1979.
}

(C) ETD - Educação Temática Digital, Campinas, SP, v.6, n.1, p.10-22 , dez. 2004 - ISSN: 1676-2592. 
não, se transformaram, por causa da popularização das tecnologias de informação, em atividades cotidianas e de domínio comum.

As linguagens documentárias e/ou a indexação sempre foram objeto de pesquisa da área de Documentação, Biblioteconomia, Ciência da Informação e Terminologia. No entanto, essa produção intelectual é ignorada por usuários e técnicos que desenvolvem seu trabalho não levando em consideração ponderações de antigos manuais e atuais artigos de periódicos e trabalhos acadêmicos. A importância da discussão da palavra enquanto fonte de sentido, em contextos documentários, incorporando algumas contribuições da semiologia de Saussure e da semiótica de Peirce é pesquisada por Lara (1993). Concluindo a autora que "as representações documentárias são elementos - chave de comunicação mediática em sistemas documentários. Se nossos catálogos e/ou índices forem apenas listas de palavras isoladas, dificilmente essa mediação se fará de forma consistente" (LARA, 1983, p. 226).

A linguagem de indexação é uma importante decisão a ser tomada na elaboração de uma política de indexação: Cesarino e Pinto (1978) apontam o papel das linguagens de indexação como instrumento controlador de vocabulário nos sistemas de recuperação de informação:

Todo procedimento de Recuperação de Informações é ligado à manipulação de "classes". Quando indexamos um documento, estamos colocando-o em uma classe determinada. Para facilitar o processo, cada classe recebe um "nome", que é chamado "termo indexador". Ao conjunto de termos indexadores chamamos Linguagens de Recuperação de Informações ou Linguagens de Indexação (CESARINO ; PINTO, 1978, p. 271).

No entanto, qual a especificidade da indexação de imagens?

Freqüentemente, refletir sobre a imagem não consiste em produzir imagens, mas sim em produzir palavras. Nesta situação, pode-se perceber (e é a reação mais difundida) um clássico fenômeno de metalinguagem: a língua serve de metalinguagem às mais diversas linguagens-objetos, e mesmo àquelas que não são lingüísticas (MERTZ, 1974, p.12).

O Pesquisador de Imagens é um pesquisador de palavras. Quando busca uma imagem deve precisar uma expressão de busca para encontrar a imagem desejada. Quando descreve as imagens atua com as ferramentas da linguagem para denotar e conotar uma determinada imagens. E ainda quando analisa as imagens o faz através da linguagem. No entanto, as pesquisas de imagens quer seja pelo pesquisador ou pelo indexador pressupõem particularidades específicas. 


\section{A GARANTIA LITERÁRIA E ENDOSSO DOS USUÁRIOS NA PESQUISA DE IMAGENS EM ARTES}

A indexação não é uma atividade mecânica, é ela um processo de produção de sentidos, lugar privilegiado para a "atuação humana".

A contextualização de um acervo ou de um Banco de Dados, em uma área de conhecimento, é o primeiro passo para qualquer análise e neste caso específico, vamos falar em Imagens em Artes. Dessa forma, todo um universo de informações será já de inicio negligenciado em nosso trabalho.

Para Rodriguez (1995, p. 352), os problemas surgidos na elaboração de uma iconoteca poderiam não estar relacionados, ou não unicamente, com questões tecnológicas concluindo que:

- os modos de classificação e arquivamento que chamamos tradicionais, nos quais se operam a partir da consideração dos traços daquilo que se deseja classificar, ou de seus traços pertinentes, podem parecer inúteis ou limitados quando a matéria com que trabalhamos é diferente daquela sobre a qual nos acostumamos a vê-la aplicada;

- um modo de classificação pode comportar uma visão de mundo, e seu uso deve partir então dessa consideração;

- surgem dificuldades quando desejamos elaborar um arquivo de imagens atendendo aos seus traços, se quisermos que o uso posterior desse arquivo seja versátil;

- um recorte importante de qualquer imagem é o seu significado, e este é múltiplo e dependente de seu contexto.

Concordamos com o autor, no entanto, a terminologia ${ }^{5}$ da área propicia a garantia literária, esta terminologia deve ser sempre atualizada e validada pelos usuários através de levantamentos terminológicos. Sendo que: conhecer um domínio de uma área é conhecer suas expressões lingüísticas, ou seja, conhecer a carga semântica de cada "unidade significativa". A carga semântica não está explícita nos termos, mas envolvida em um processo histórico, que se consegue pelo desenvolvimento do contexto da área. No caso específico da área de Artes, a terminologia está amparada na História da Arte enquanto processo de produção do conhecimento, ou seja, em processo em construção.

\footnotetext{
${ }^{5}$ A Terminologia estuda os termos de uma área do conhecimento e, portanto, estabelece as características discursivas de cada uma das disciplinas, ou seja, descreve os usos terminológicos de filiação discursiva.
} 
Os discursos das disciplinas do saber (VÁLIO ; OLIVEIRA, 2001) desenvolvemse em um processo de legitimação do conhecimento em uma determinada área, atribuindo a ela o estatuto de Ciência. A legitimação do conhecimento é alcançado através das definições de objeto de estudo, de metodologias de pesquisa, de uma terminologia específica, que qualifica o próprio estatuto da área.

No processo do exercício discursivo, o transmitir a informação e o fixar os conhecimentos, que são articulados pelas autoridades da área, sedimenta o saber científico.

A argumentação, que torna o conhecimento de fato, promovida por questões pontuais, compõe o saber consolidado. Esse conhecimento, de conteúdo referencial, constituise no saber institucionalizado e legitimado.

Sendo, assim, o estabelecimento de uma cientificidade pode ser conseguido por meio de enfoques diferenciados, que permitem a expansão de sentidos. Os sentidos, expandidos por discursos polêmicos, em sua intertextualidade, são limitados em sua produção naquilo que é esperado em sua recepção discursiva.

Pesquisas sobre indexação e terminologia em Artes (OLIVEIRA, 2000 ; STREHL, 1999) apontam o alto índice de ocorrência de modificadores geográficos, cronológicos e históricos na terminologia da área de Artes. Sendo que a consistência da indexação realizada na base de dados de uma biblioteca universitária especializada em artes plásticas, música e teatro, é avaliada por Strehl (1998), concluindo a pesquisadora que "a falta de uma política de indexação e de um tesauro específico nas áreas estudadas são fatores que estão relacionados diretamente com os problemas identificados para realização de uma indexação coerente e consistente" (STREHL, 1998, p.15).

Esta dificuldade está ligada diretamente a própria área do conhecimento, enquanto que é um saber pautado na baixa codificação, na linha que separa a Arte e a Ciência. A partir das identidades e similaridades, Plaza procura estabelecer as diferenças de metodologia entre arte e ciência. "Enquanto a ciência procura a determinação na hipercodificação, a arte, em contraposição, tende ao singular e a baixa codificação, pois a arte não é linguagem (stricto sensu)" (PLAZA, 1996, p.26). 
Segundo o autor "o estado semântico está determinado pela convenção e o estado estético está determinado pela singularidade, debilidade e ambigüidade" (PLAZA, 1996, p.25).

Em um trabalho de busca de novas metodologias de tratamento e recuperação da informação em imagens fotográficas, Manini (1998, p.99) indica que "a linha mestra de um trabalho de análise documentária de imagens seja a contextualização das fotografias que se pretende catalogar dentro das temáticas principais existentes na instituição", e conclui ainda que a:

Análise Documentária de fotografias tem como objetivo representar, de maneira condensada, o conteúdo informacional da imagem, através de resumo e/ou indexação e, caso seja pertinente, complementar a análise incluindo dados relativos à expressão fotográfica (MANINI, 1998, p.100).

A política de indexação, suas variáveis e requisitos são analisadas por Carneiro (1985). Segundo a autora, na implantação de um serviço de indexação há que se levar em conta um grande número de variáveis, apresentando a seguir os requisitos para o estabelecimento de uma política de indexação: 1. características e objetivos da organização; 2. identificação da clientela, 3. recursos humanos, materiais e financeiros, que delimitam o funcionamento de um sistema de recuperação de informações. Acrescenta ainda os elementos a considerar na elaboração de uma política de Indexação: cobertura de assuntos, seleção e aquisição de documentos, o processo de indexação (níveis de exaustividade e especificidade), capacidade de revocação e precisão, linguagem, estratégia de busca, forma de saída, tempo de resposta do sistema, avaliação do sistema.

\section{SUBJETIVIDADE, CONOTAÇÃO E LEITURA NA PESQUISA DE IMAGENS EM ARTES}

Produzir conhecimentos é da natureza da intervenção intelectual sobre objetos simbólicos. No caso específico da área de artes, a matéria prima refere-se à estética. "Arte não se doa ao mundo como informação semântica, mas como informação estética" (PLAZA, 1996, p.26). Para Gomes (1989) existe uma impossibilidade de indexação da informação estética, sendo apenas possível a indexação manual ou automática para a informação científica e técnica, isto é, de natureza semântica e lingüística em oposição ao 'estético'. 
O binômio 'Semântico-e-linguístico' deve ser enfatizado porque, embora a uma informação estética se possa adicionar, a posteriori e de forma arbitrária, um componente semântico, apesar disso, sua indexação apresenta problema distinto daquela que é apenas semântica e lingüística ao mesmo tempo. Dado a sua natureza, a informação estética foge ao controle do indexador, já que tal "leitura" é extremamente individual (GOMES, 1989, p. 163).

Se a informação em Artes é estética e consequentemente submetida a posteriori ao debate semântico e lingüístico não perde aí sua característica de subjetividade? Qual leitura deve ser feita para a indexação em Artes?

Lucas (2000, p. 85) faz uma analise do discurso que descreve a leitura do profissional bibliotecário:

- o discurso que descreve a leitura do bibliotecário procura caracterizá-lo como científica, logo neutra e apolítica;

- a leitura do bibliotecário simula o modo de produção industrial, buscando produtividade, rapidez, não dando margem à reflexão e ao acúmulo de conhecimento por parte do bibliotecário;

- $\quad$ esta leitura deseja-se rigorosa, transparente. O sujeito-leitor não deve interpretar. A leitura deve se literal, apreendendo o conteúdo do texto e produzindo representações do mesmo, simulacros, dando-lhe unidade por meio de palavraschave;

- a leitura deve ser eficaz, administrável, controlada por meio de treinamento rigorosos, obedecendo sempre a regras de objetividade.

Essa leitura científica, neutra, apolítica, produtiva, rápida, sem reflexão, rigorosa, transparente, eficaz, administrável, objetiva é incompatível com a necessária pesquisa para a indexação de imagens em artes. A leitura do bibliotecário ou indexador não pode ser tão regulamentada, não pode e "não consegue ser" como vemos em Lucas:

observamos a leitura do bibliotecário em sua prática de indexação. Observamos de que lugar lê esse leitor. Aí constatamos como o sujeito leitor emerge, apesar de sua leitura estar subsumida aos interesses da instituição, apesar das linguagens documentárias (controle de vocabulário, de terminologia), trazendo consigo suas histórias de leitura (LUCAS, p. 86).

A leitura para indexação de imagens em Artes pressupõe a predisposição para a pesquisa. A pesquisa de identificação de imagens pressupõe uma série de etapas. Fonte Imagética: Aqui podemos responder a dois tipos de perguntas: De onde é essa imagem? O que é essa imagem? Essa imagem é o resultado de uma fotografia? Se sim, o que foi fotografado? Um quadro ou uma escultura em um museu? Ou a imagem de um quadro ou 
escultura em um livro de História da Arte ou em um Catálogo de Exposição? Segundo: Quais livros utilizei para responder as questões anteriores? Ou seja, quais livros me serviram como fontes de pesquisa para identificação da imagem.

Para a composição dos descritores a pesquisa deve se estender ao domínio da Arte, técnicas empregadas, Artista autor, Biografia, Modificadores históricos, geográficos e cronológicos. Esse conjunto de informações se consegue com pesquisa. Lucas (2000, p. 85 86) aponta para a divisão do trabalho de leitura da Idade Média onde havia a divisão entre os indivíduos autorizados a ler, falar e escrever em seus nomes (cientistas, os intelectuais, os críticos) e os outros (classificadores, indexadores, codificadores) leitores anônimos, cujo trabalho visava sustentar a leitura dos primeiros.

se esta leitura se quer rápida, produtiva, ela sacrifica a reflexão, impossibilita a interpretação, sem a qual esta leitura não consegue apreender os sentidos do documento e, por sua vez, encontrar os descritores que seriam as palavras indicadoras das múltiplas possibilidades de leitura (LUCAS, 2000, p. 86).

No caso específico da leitura para indexação de imagens em artes essa divisão impossibilita o próprio processo do trabalho.

\section{CONCLUSÕES}

O Pesquisador de Imagens é sempre um pesquisador de palavras. A indexação de imagens em Artes pressupõe pesquisa e atribuição de conceitos que estão sujeitos a leitura do indexador, ideologias, cultura e subjetividade. É sempre um recorte amparado no contexto. O profissional precisa do endosso do usuário e da garantia literária.

Não concordamos com Rodriguez com uma indexação baseada unicamente na conotação dada pelos usuários, embora a indexação em artes esteja submetida a conotação, a baixa codificação e a subjetividade. Acreditamos que o discurso se produz na intertextualidade, no conflito, na relação de um texto com outros textos e na produção intelectual daquele que é pesquisador de imagens e simultaneamente pesquisador de palavras. 
Esse discurso está disponível, materializado, na literatura da área através de seus dicionários, enciclopédias, manuais, artigos de periódicos, catálogos de exposição, manuais de história da arte, etc. Nesses instrumentos podemos buscar a garantia literária.

Concordamos com Rodriguez sobre a fragilidade de uma análise baseada apenas no desenvolvimento das tecnologias (enquanto digitalização de imagens ou elaboração de base de dados) quando se pensa em um Banco de Dados de Imagens em Artes. A temática da terminologia enquanto área do conhecimento abriga um debate interno e é nesse debate que estão surgindo as soluções e propostas que superam a ênfase ingênua na tecnologia.

\section{REFERÊNCIAS}

CARNEIRO, M. V. Diretrizes para uma política de Indexação. Revista da Escola de Biblioteconomia da UFMG, Belo Horizonte, v. 14, n. 2, p.221-241,set.1985.

CESARINO, M. A. N. ; PINTO, M. C. M. F. Cabeçalho de assunto como linguagem de indexação. Revista da Escola de Biblioteconomia da UFMG, Belo Horizonte, v. 7, n. 2, p.268-288, 1978.

GOMES, H. E. O indexador face às novas tecnologias de informação.

Transinformação, Campinas, v.2, n. 1, maio/ago. p.161-17, 1989.

GOMES, H. E., GUSMÃO, H. R. Guia prático para a elaboração de índice. Niterói: GBIDCSH da APB-RJ, 1983.

LANCASTER, F.W. Indexação e resumos: teoria e prática. Brasília: Briquet de Lemos/Livros, 1993.

LARA, M. L. G. de. Algumas contribuições da semiologia e da semiótica para a análise das linguagens documentárias. Ciência da Informação, v.22, n. 3, p. 223-226, set./dez. 1993.

LUCAS, C. R. Leitura e interpretação em biblioteconomia. Campinas: UNICAMP, 2000.

MANINI, M. Análise documentária de imagens: documentos fotográficos e

Indicialidade. Campinas: Cadernos da Pós-Graduação, v.2, n. 2, 1998.

MANINI, M. Os usos da iconografia no ensino e na pesquisa: o acervo multimeios do arquivo Edgard Leuenroth. Campinas: Cadernos AEL, n.5/6, 1997.

METZ, C. et al. A Análise das imagens. Petrópolis: Vozes, 1974.

OLIVEIRA, V.F.F. Indexação de Audiovisual na Biblioteca de Artes da UNICAMP: Avaliação da terminologia. Campinas: PUC - Campinas, 2000. (monografia - Bacharel em Biblioteconomia). 
PINHEIRO, L. V. R. ; VIRUEZ, G. V., DIAS, M. Sistema de Informação em Arte e Atividades Culturais (Iara): aspectos políticos, institucionais, técnicos e tecnológicos. Brasília: Ciência da Informação. v. 23, 3, p.327-334, set./dez. 1994.

PLAZA, J.. Arte/Ciência uma consciência. Revista de Comunicações e Artes. São Paulo. v. 19, n. 29, p.11-23, set./dez, 1996.

RODRIGUEZ, V. A Iconoteca Inteligente. In: Samain, E. O fotográfico. São Paulo: Hucitec, 1998.

STREHL, L. Avaliação da consistência da indexação realizada em uma biblioteca universitária de artes. Ciência da Informação [on-line], v. 27, n. 3, Brasília, set. 1998.

Disponível em: <: http://www. scielo.br>, Acesso em 19 nov. 1999.

TÁLAMO, M. F. G. M. et al. Contribuição da terminologia para a elaboração de tesauros. Ciência da Informação. v. 21, n. 3, p.197-200, dez. 1997.

VÁLIO, E. B. M. ; OLIVEIRA, V.F.F. Terminologia da Ciência da Informação: abordagem da análise do discurso. Perspectivas em Ciências da Informação. Belo Horizonte, v.8, n.2, p. 114-133, jul-dez.2003. 